\title{
Effects of the venom of the rhinoceros horned viper (Bitis nasicornis) on blood coagulation, platelet aggregation, and fibrinolysis
}

\author{
N. MacKAY ${ }^{1}$, J. C. FERGUSON, AND G. P. McNICOL
}

From the University of East Africa, Medical School Extension, Kenyatta National Hospital, Nairobi, Kenya, the University Department of Materia Medica, Stobhill General Hospital, Glasgow, and the University Department of Medicine, The Royal Infirmary, Glasgow

SYNOPSIS The venom of the rhinoceros horned viper (Bitis nasicornis) has been studied in vitro and has been shown to be anticoagulant. This action appeared to be due to an effect on both the extrinsic and intrinsic blood thromboplastin mechanisms. The venom was also proteolytic and in purified caseinolytic systems activated plasminogen, enhanced the activation of plasminogen by streptokinase, and potentiated the action of plasmin. In the euglobulin clot lysis system high concentrations of venom produced inhibition. The crude venom increased platelet adhesiveness but in high concentrations delayed the snowstorm effect in the Chandler's tube system and inhibited platelet jadenosine diphosphate reactivity. Passage through carboxymethylcellulose yielded six fractions. One possessed anticoagulant activity, inhibited plasmin, and increased the optical density of platelet-rich plasma. The other five fractions shortened the plasma recalcification time but had no effect on plasmin activity. Four fractions aggregated platelets and enhanced platelet adenosine diphosphate reactivity.

The rhinoceros horned viper is distributed in a band across Africa, stretching from West Africa to western Kenya (Bücherl, Buckley, and Deulofeu, 1968). As its name implies it is characterized by a horn on its maxilla. The venom of this snake has been studied by Kirk and Corkill (1946) who found that injected into mice the venom produced local haemorrhage, and in the animals which died punctate haemorrhages were found in the kidneys and lungs. In vitro, the venom seemed to have no effect on the whole blood clotting time, but proteolytic activity was observed when the venom was incubated with gelatin.

The present communication reports the findings of more detailed studies of the effects of the venom of the rhinoceros horned viper on the haemostatic mechanism.

${ }^{2}$ Please send requests for reprints to N. MacKay, Department of Materia Medica, Stobhill General Hospital, Glasgow, W1.

Received for publication 20 May 1970.

\section{Methods}

WHOLE BLOOD COAGULATION TIME

This was determined as described by Biggs and MacFarlane (1963). Of the venom solution, 0.1 ml was added to each tube and in the control system this was replaced by $0 \cdot 1 \mathrm{ml}$ saline.

PLASMA RECALCIFICATION TIMES

These were as described by Biggs and MacFarlane (1963). In the test system various concentrations of venom were substituted for saline.

THROMBIN-FIBRINOGEN DILUTION CURVE The curve was constructed as described by Biggs and MacFarlane (1963).

THROMBIN GENERATION TEST

The method of Pitney and Dacie (1953) was used. 
PROTHROMBIN CONSUMPTION TEST

Merskey's method (1950) was used. Saline or venom in saline, $0 \cdot 1 \mathrm{ml}$, was added.

THROMBOPLASTIN GENERATION TEST

To the standard test system of Biggs and Douglas (1953) was added $0.2 \mathrm{ml}$ saline or $0.2 \mathrm{ml}$ of venom solution in saline. The destruction of formed blood thromboplastin was measured by generating blood thromboplastin in the standard mixture for five minutes and adding $0.5 \mathrm{ml}$ venom (or saline). The decay of thromboplastic activity was then measured by transferring aliquots into substrate plasma at intervals.

ONE-STAGE 'PROTHROMBIN TIMES'

Venom (or saline), $0.1 \mathrm{ml}$, was added to the test system of Douglas (1962).

\section{EUGLOBULIN CLOT LYSIS TIME}

This was measured by the method of Nilsson and Olow (1962). Saline, $0 \cdot 1 \mathrm{ml}$, was added to the control system and $0.1 \mathrm{ml}$ venom in saline in increasing concentration was added to the test system. The results are expressed in arbitrary units of activity derived from a double logarithmic plot, 1 unit representing a lysis time of 300 minutes.

\section{CASEINOLYTIC ASSAYS}

These were carried out by the method of Remmert and Cohen (1949) as modified by Alkjaersig (1960); the method is described by McNicol and Douglas (1964), 0.1 M phosphate buffer being substituted for acid and alkali. Where venom was used, $0.5 \mathrm{ml}$ of a $10 \mathrm{mg} / \mathrm{ml}$ solution in saline was incorporated into the system in place of $0.5 \mathrm{ml}$ of the phosphate buffer being used in the assay. Similarly, buffer was substituted for streptokinase and plasminogen in the experiments in which these reagents were omitted. Results are expressed in casein units $/ \mathrm{ml}$. The effect on plasmin activity was assessed using a similar protocol. Plasminogen and streptokinase were omitted and replaced by preformed human plasmin (A.B. Kabi, Stockholm, Sweden).

PLATELET AGgREGATION IN THE

CHANDLER'S TUBE

This was measured by a modification of the method of Chandler (1958) as described by Cunningham, McNicol, and Douglas (1965).

PLATELET ADP REACTIVITY

This was measured by the method of Born and Cross (1963), with the addition of $0.5 \mathrm{ml}$ saline to the control system and $0.5 \mathrm{ml}$ venom solution to the test system. Adenosine diphosphate was added to produce a final concentration of $0.5^{5}$ $\mu \mathrm{g} / \mathrm{ml}$.

PLATELET ADHESIVENESS This was measured by the method of Hellemp (1960).

VENOM FRACTIONATION

This procedure was carried out using a carboxymethylcellulose column (CM 22). A total of $150 \mathrm{mg}$ venom in $3.75 \mathrm{ml}$ of saline was applied to the top of the column and in a stepwise gradient barbital-acetate buffers of increasing $p H\left(4 \cdot 0-9 \cdot 0 \frac{\overline{8}}{6}\right.$ were used for elution. The effluent was constantlyij monitored in an ultraviolet spectrophotomete (LKB Uvicord) and the protein-containing fractions were freeze dried after dialysis againsto distilled water for 24 hours at $4^{\circ} \mathrm{C}$.

\section{Materials}

Venom of Bitis nasicornis was supplied in dessi $\vec{\vartheta}$ cator dried form by $\mathrm{Mr}$ J. H. Leakey, Lake Baringo, Kenya. Before use it was dissolved inf saline. In the stock solution, venom was presen in a concentration of $10 \mathrm{mg} / \mathrm{ml}$.

Purified preparations of human plasminogen anç of plasmin, grade B, were supplied by A.B. Kabi $\stackrel{\circledR}{\mathcal{D}}$ Stockholm, Sweden, as also was streptokinase $\overrightarrow{\overline{\widehat{T}}}$ Thrombin topical was supplied by Parke Davis and adenosine diphosphate (ADP) by the Sigma? Chemical Company, St. Louis, Mo.

\section{Results}

WHOLE BLOOD COAGULATION TIME Blood in a control tube to which saline had been? added coagulated in four minutes. The addition of venom in increasing concentrations causedE. prolongation of the coagulation time and at of venom concentration of $900 \mu \mathrm{g} / \mathrm{ml}$ the coagulation time was 11 minutes.

PLASMA RECALCIFICATION TIMES The results are shown in Table $I$. At a final cons

\begin{tabular}{|c|c|c|c|c|c|}
\hline & \multirow[b]{2}{*}{ Saline } & \multicolumn{4}{|c|}{ Venom Concentration $(\mu \mathrm{g} / \mathrm{ml})$} \\
\hline & & 3 & 13 & 52 & 208 \\
\hline Clotting times (seconds) & 116 & 115 & 180 & 325 & $>600$ \\
\hline
\end{tabular}

Table I Plasma recalcification times with increasing concentrations of venom 


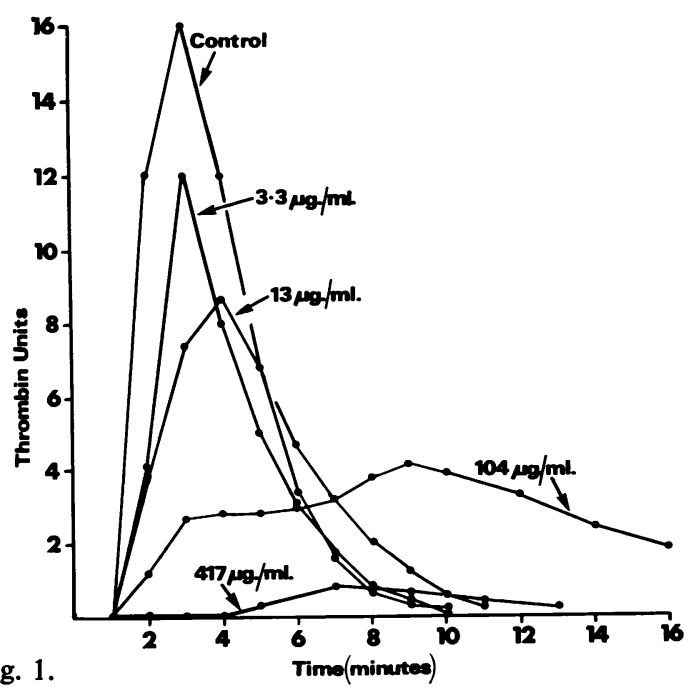

Fig. 1.

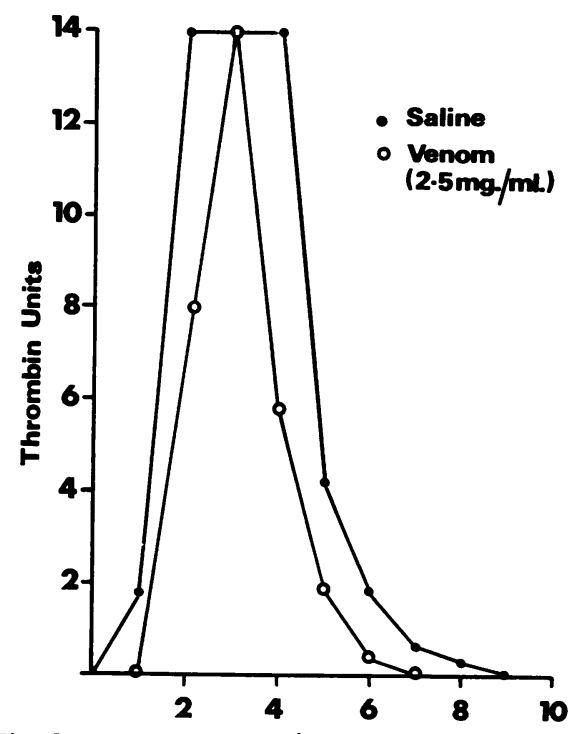

Fig. 2.

Time(minutes)

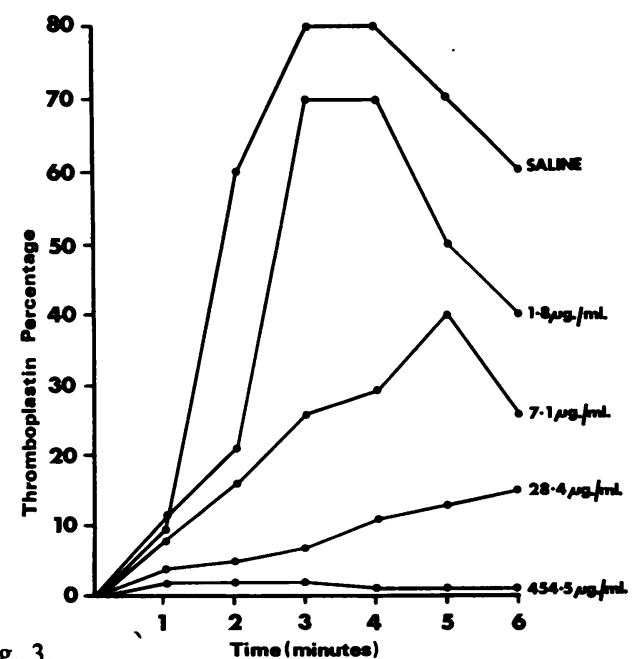

Fig. 1 Effect of various concentrations of venom on thrombin generation.

Fig. 2 Effect of venom on the interaction of thrombin? and fibrinogen.

Fig. 3 Effect of various concentrations of venom on thromboplastin generation.

centration of venom of $208 \mu \mathrm{g} / \mathrm{ml}$ the plasma was rendered incoagulable.

THROMBIN GENERATION TEST

The results are shown in Figure 1. In comparisonio with the control system thrombin generation was progressively impaired and delayed by increasing ${ }_{0}^{\circ}$ the concentration of venom in the incubation? mixture.

THROMBIN-FIBRINOGEN REACTION IN THE PRESENCE OF VENOM

In order to test the possibility that the venom was $\overrightarrow{0}$ interfering with the conversion of fibrinogen to fibrin, human thrombin was generated from: plasma and aliquots were transferred to two serieso of tubes, one containing fibrinogen-saline and the other fibrinogen-venom. The final concentration of venom in the substrate was $2.5 \mathrm{mg} / \mathrm{ml}$. The results are illustrated in Figure 2. There is no evidence that the venom interferes with the conver-ō sion of fibrinogen to fibrin under the influence of thrombin.

PROTHROMBIN CONSUMPTION

In the control system to which saline had been added, the prothrombin consumption index was less than $5 \%$. When venom was present in a₹ concentration of $900 \mu \mathrm{g} / \mathrm{ml}$ the index was $92 \%$,응 indicating grossly defective prothrombin consumption.

THROMBOPLASTIN GENERATION TEST The results are shown in Figure 3. With increasing concentration of venom there was progressive diminution in the amount of thromboplastine detectable in aliquots from the incubation mixture.

DESTRUCTION OF FORMED BLOOD THROMBO-O PLASTIN

The results illustrated in Fig. 4 indicate that the decay of formed thromboplastin is greater in the presence of venom than in the saline control. The amount of thromboplastin detected is progress $-\frac{0}{0}$ ively reduced as the concentration of venom in the incubation mixture is increased. 


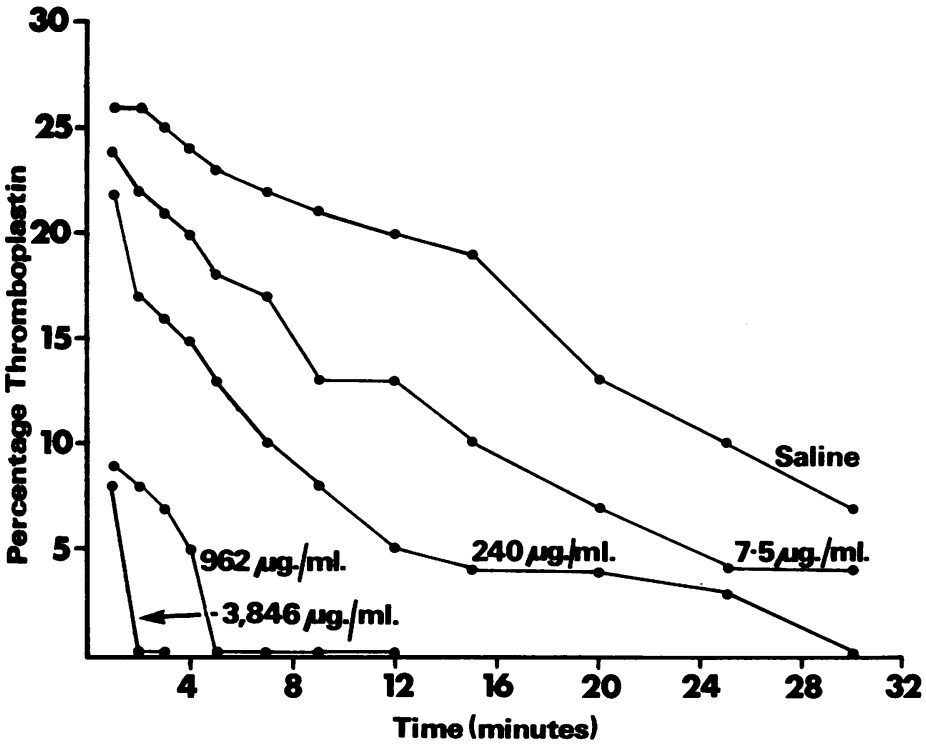

Fig. 4 Effect of various concentrations of venom on formed blood thromboplastin.

ONE-STAGE 'PROTHROMBIN' TIME

In the control system to which saline had been added the clotting time was 14 seconds (Table II). When venom was present in a final concentration of $2,500 \mu \mathrm{g} / \mathrm{ml}$ floccules formed at 30 seconds, but no proper clot was formed.

\begin{tabular}{lllllc}
\hline & \multicolumn{4}{c}{ Venom Concentration $(\mu \mathrm{g} / \mathrm{ml})$} \\
\cline { 3 - 6 } & Saline & 39 & 156 & 625 & 2,500 \\
\hline Clotting times (seconds) & 14 & 13 & 13 & 19 & 30
\end{tabular}

Table II One-stage 'prothrombin' time with increasing concentrations of venom

INCUBATION OF FIBRINOGEN WITH VENOM The results are illustrated in Figure 5. In the control system to which saline had been added in place of venom, the thrombin clotting time did not alter significantly during the experiment and there was no evidence of proteolysis as demonstrated by tyrosine release. In the test system to which venom had been added the thrombin clotting time was rapidly prolonged and after incubation for only one and a half hours, the solution was incoagulable. Over this period of time there was a progressive increase in the tyrosine content of the solution reflecting the breakdown of fibrinogen by the venom. of concentrations with euglobulin clot lysis

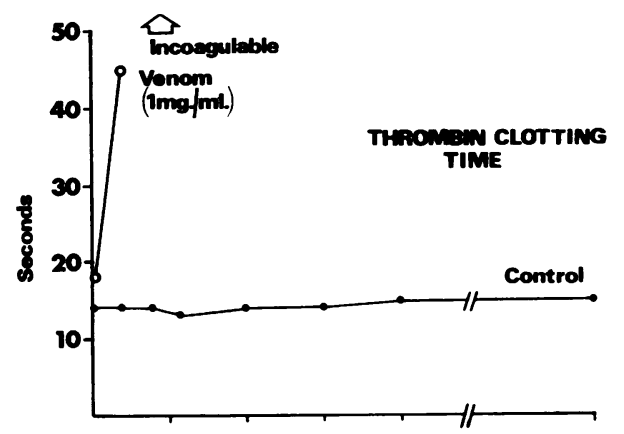

Fig. 5 Effect of venom on purified fibrinogen. The upper part of the figure shows the effect of the venom on the thrombin clotting time of the incubation mixture. The lower part demonstrates the fibrinogenolytic effect of the venom.

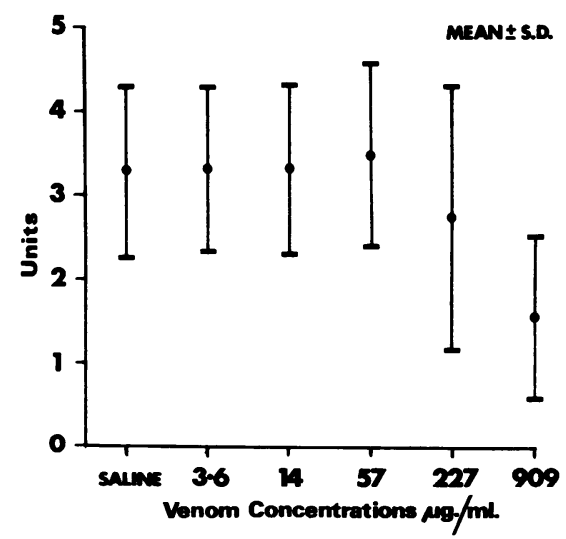

Fig. 6 Effect of various concentrations of venom on euglobulin clot lysis activity. The result in each experiment is the mean and standard deviation of seven duplicate estimations.

systems a biphasic response was obtained (Fig. 6 When present in low concentrations 3.6 and $1 \frac{16}{6}$ $\mu \mathrm{g} / \mathrm{ml})$ the euglobulin clot lysis activity was not significantly different from a control system to which saline had been added in place of venom. Af a concentration of $57 \mu \mathrm{g} / \mathrm{ml}$ there was slight, but significant enhancement of lytic activity as corfs 


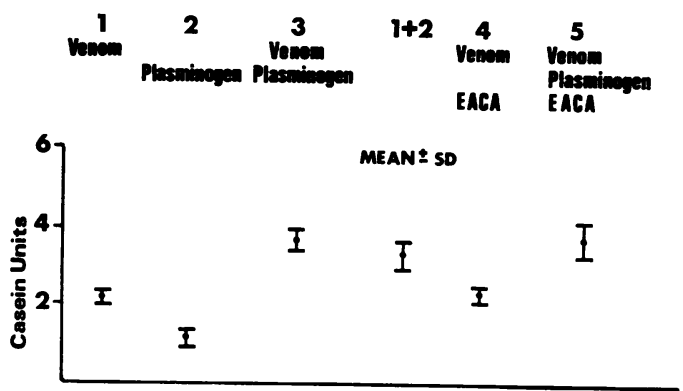

Fig. 7 Effect of venom on plasminogen and the effects of EACA on the proteinolytic action of venom and its ability to activate plasminogen. The result in each experiment is the mean and standard deviation of seven duplicate estimations.

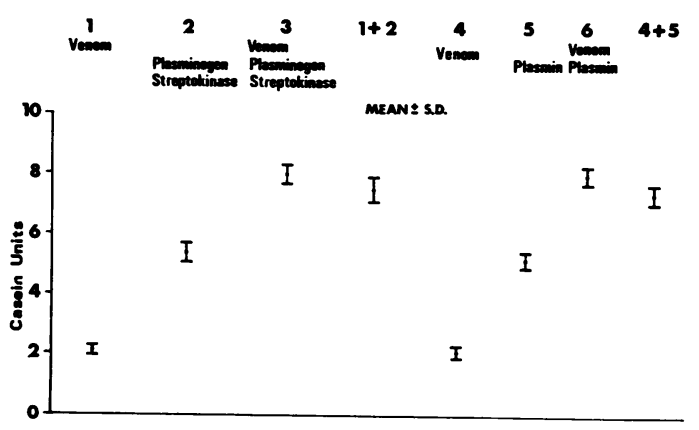

Fig. 8 Effect of venom on caseinolytic assays incorporating plasminogen, streptokinase, and plasmin. The result in each experiment represents the mean and standard deviation of seven duplicate estimations.

pared with the control system $(\mathrm{t}=2.71 ; 0.02<\mathrm{P}$ $<0.05)$. Venom at a concentration $227 \mu \mathrm{g} / \mathrm{ml}$ reduced euglobulin clot lysis activity, but this reduction was not statistically significant when compared with control $(\mathrm{t}=1 \cdot 87 ; 0 \cdot 10<\mathrm{P}<0.02)$. At a concentration of $909 \mu \mathrm{g} / \mathrm{ml}$, euglobulin clot lysis activity was markedly inhibited $(\mathrm{t}=6.00$; $P<0.001)$.

\section{CASEINOLYTIC ASSAYS}

The results are shown in Figures 7 and 8. The venom is proteolytic and activates plasminogen (Fig. 7). The caseinolytic activity observed when the venom and plasminogen are incubated together is significantly greater than what would be anticipated from the addition of the caseinolytic activities obtained when venom and plasminogen were separately incubated with casein $(t=2.69$; $0.025<P<0.05$ ). Slight caseinolysis occurring in the presence of plasminogen alone is due to spontaneous activation of the plasminogen. The proteolytic activity of the venom and its ability to activate plasminogen were not significantly altered by the presence of aminocaproic acid (EACA). In a $\frac{\varrho}{\bar{F}}$ further series of experiments streptokinase and 0 plasminogen were incubated together with casein in one set of experiments, and streptokinase, . plasminogen, and venom were incubated together $\vec{F}$ with casein in the other. The results are shown in Figure 8 (left hand section). When all three? constituents were present, the caseinolytic activity $\frac{\overline{\bar{D}}}{\bar{D}}$ was greater than what would have been anticipated from the summation of the activities $\varrho$ observed in the experiments in which venom wases present alone and plasminogen and streptokinase $-\vec{\circ}$ together. This difference, though small, is signifi- cant $(\mathrm{t}=2.46 ; 0.025<\mathrm{P}<0.05)$.

In a further series of experiments (Fig. $8, \stackrel{\circ}{\circ}$ right hand section), when venom and plasmino were incubated separately and together the N caseinolytic activity observed when venom andio plasmin were incubated together with casein was greater than what would have been expected from ${ }^{\circ}$ the summation of their separate activities $(t=$ 을 $4.77 ; 0.001<\mathrm{P}<0.005)$.

\section{PLATELET FUNCTION}

When crude venom was used in the Chandler's tube system (1958), high concentrations delayed $\overrightarrow{0}$ the appearance of the snowstorm effect, but lower concentrations had a variable effect.

In high concentrations the venom inhibited platelet ADP reactivity. When venom was added to platelet-rich plasma in the Born system, with-o out the addition of ADP, no effect on the platelets $\frac{\mathscr{}}{\square}$ was observed using high or low concentrations of $\bigcirc$ venom, but in the presence of intermediate con- $\overrightarrow{\overrightarrow{0}}$ centrations of venom, platelet aggregation 3 occurred.

Platelet adhesiveness in whole blood, using the Hellem technique (1960), was increased over ac wide range of concentrations of venom. Using: platelet-rich plasma, increased adhesiveness was also observed when venom was present in higher concentrations.

\section{FRACTIONATION STUDIES}

The results of fractionation are illustrated in Figure 9. Six fractions were taken for furthero study.

\section{Plasma recalcification times}

The results are shown in Table III. Fraction 6 showed marked anticoagulant activity. The other five fractions shortened the recalcification times

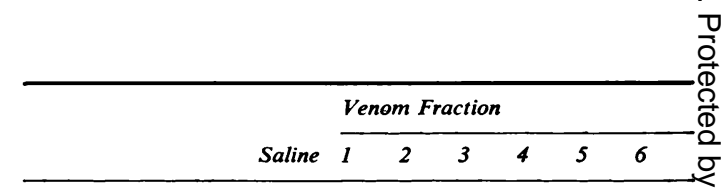

$\begin{array}{llllllll}\text { Clotting times (seconds) } & 166 & 160 & 154 & 134 & 160 & 140 & >600 \Omega\end{array}$

Table III Effects of venom fractions on plasma recalcification time 
CM22 CHROMATOGRAPHY
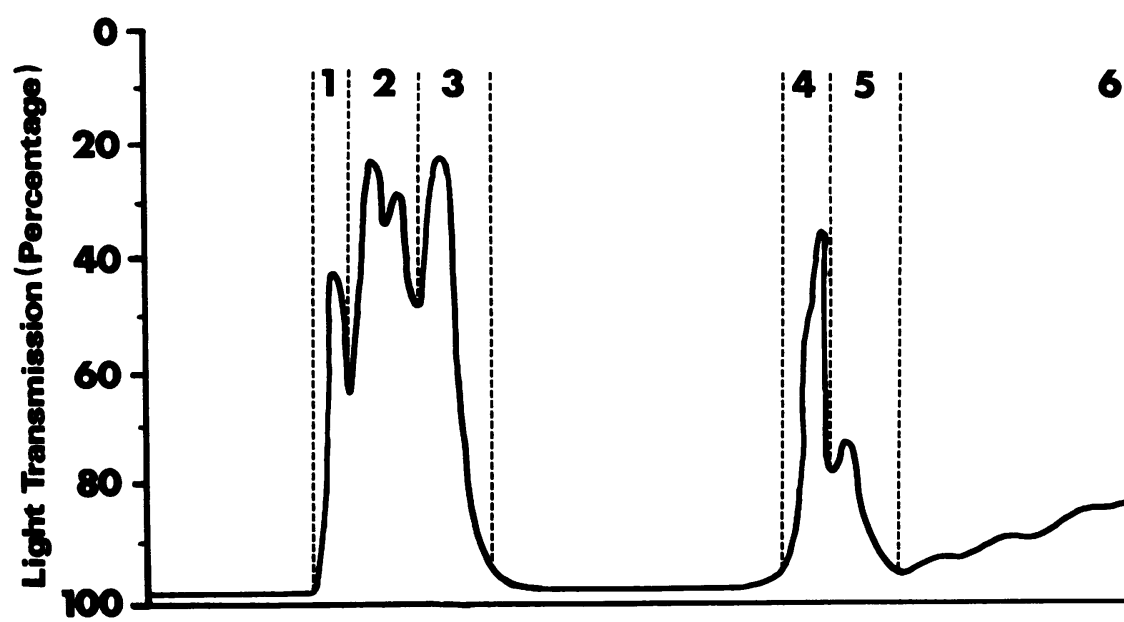

Fig. 9 Fractionation of the crude venom of Bitis nasicornis using carboxymethylcellulose 22.

as compared with a control system to which saline had been added in place of venom.

\section{Effects on plasmin}

Fraction 6 inhibited plasmin activity by about $18 \%$ (Table IV). The other fractions had a negligible effect on the activity of plasmin.

\begin{tabular}{llll}
\hline Fraction & Plasmin & $\begin{array}{l}\text { Plasmin plus } \\
\text { Venom }\end{array}$ & Venom \\
\hline 1 & $5 \cdot 30$ & $5 \cdot 70$ & $0 \cdot 75$ \\
2 & $5 \cdot 30$ & $5 \cdot 60$ & 0.40 \\
3 & $5 \cdot 30$ & $5 \cdot 50$ & $0 \cdot 35$ \\
4 & $5 \cdot 30$ & $6 \cdot 70$ & $1 \cdot 20$ \\
5 & $5 \cdot 30$ & $5 \cdot 70$ & $0 \cdot 10$ \\
6 & $5 \cdot 30$ & $4 \cdot 75$ & 0.50
\end{tabular}

Table IV Effects of venom fractions on casein and caseinolytic activity of plasmin ${ }^{1}$

${ }^{1}$ Activities expressed in casein units.

\section{Platelet ADP reactivity}

Fraction 1 inhibited platelet ADP reactivity (Fig. 10). Fractions 2-5 all had a similar action, enhancing platelet ADP reactivity as illustrated in Figure 10. Fraction 6 inhibited platelet ADP reactivity and increased the optical density of the plasma. The experiments were repeated without the addition of ADP (Fig. 11). Fraction 1 did not markedly differ from the control. Fractions 2-5 produced aggregation of platelets in the absence of ADP. Fraction 6 produced the same results as it did in the presence of ADP, increasing the optical density of the plasma, but in a further experiment, using platelet-poor plasma instead of platelet-rich plasma, the optical density was unaltered.

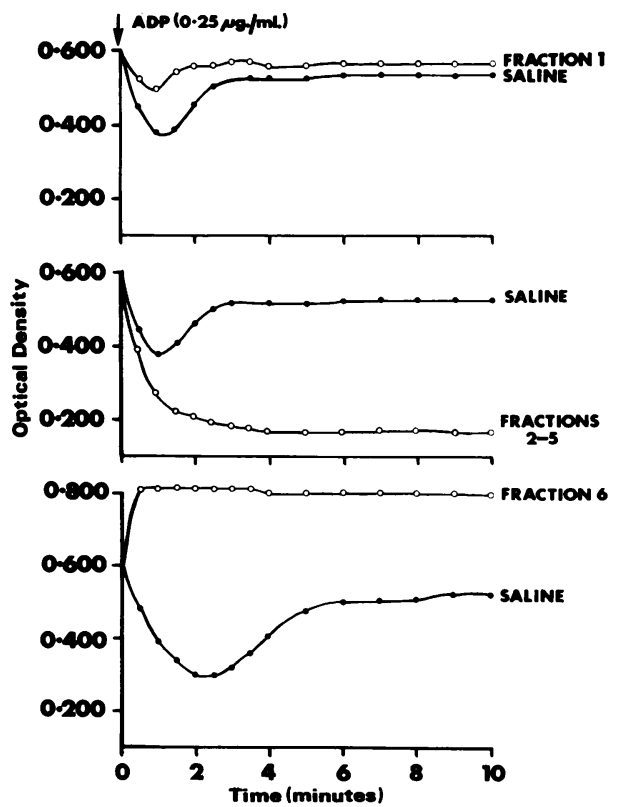

Fig. 10 Effect of venom fractions on platelet $A D P$ reactivity.

\section{Discussion}

The results show that the venom of therhinoceros horned viper is anticoagulant in vitro. This actio appears to be due to an effect on both the extrins $\overrightarrow{8}$ and intrinsic thromboplastin mechanisms, 迎 evidenced in the instance of the former by the abnormality produced in the one-stage 'pros thrombin' time and in the latter by the abnof malities in the prothrombin consumption, thron boplastin generation, and thrombin generatiog. 


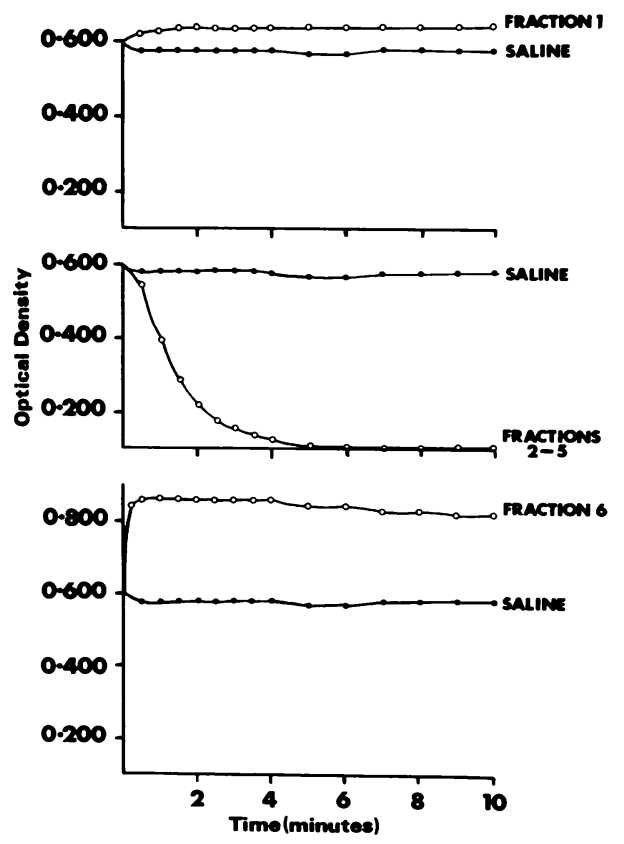

Fig. 11 Effect of venom fractions on platelet-rich plasma.

tests. The main effect is probably on the intrinsic thromboplastin mechanism, as much higher concentrations of venom were required in order to produce an effect on the one-stage 'prothrombin' time. It is likely that the venom is interfering with the production of thromboplastin, but destruction of thromboplastin as it is being formed could be a contributing factor. Kirk and Corkill (1946), using the whole blood clotting time, could demonstrate no change in blood coagulation in vitro. In the current study, the venom, in the highest concentration used, prolonged the whole blood clotting time to almost three times that of a control sample to which saline had been added in place of venom. Kirk and Corkill found evidence of haemorrhage when the venom was injected into mice and the differences in the studies in vitro are likely to be due to differences in the concentrations of venom which were used.

There was no evidence that the venom interfered directly with the conversion of fibrinogen to fibrin under the action of thrombin. On incubation of fibrinogen with venom the thrombin clotting time was prolonged, but this has been shown to be due to the digestion of fibrinogen by the venom, the breakdown products of fibrinogen digestion presumably interfering with normal fibrin polymerization.

The observation of Kirk and Corkill (1946), that the venom of the rhinoceros horned viper is proteolytic, has been confirmed in the present study using caseinolytic techniques. The venom was found to activate plasminogen and, like the venoms of Echis carinata (Forbes, Turpie, $\frac{\rho}{\bar{\Xi}}$ McNicol, and Douglas, 1966) and Dispholidus typus (MacKay, Ferguson, Ashe, Bagshawe, Forrester, and McNicol, 1969), enhanced the $\frac{\text {. }}{\text {. }}$ activation of plasminogen by streptokinase. In $\overrightarrow{\vec{F}}$ addition, the venom was found to potentiate the $\frac{\text { ? }}{-}$ action of purified plasmin in caseinolytic assays. 등 When incorporated into a euglobulin clot lysis $\overline{\frac{\sigma}{5}}$ system, increased activity was only slight and $\vec{\Phi}$ occurred at an intermediate concentration, while $\propto$ in high concentrations inhibition was observed. \% This effect could possibly be explained in the $\vec{\circ}$ presence of fractions with opposing actions, being diluted out at different rates.

Crude venom was also shown to interfere? significantly with platelet function. High concen-? trations of venom delayed platelet aggregation in $\tilde{\omega}$ the Chandler's tube system and inhibited platelet. ADP reactivity. Lower concentrations had vari- $\infty$ able effects. In the absence of ADP it was found that intermediate concentrations of venom could $\textrm{ }$ induce platelet aggregation in the Born system. $\vec{\nabla}$ The venom also had the property of increasing $\Phi$

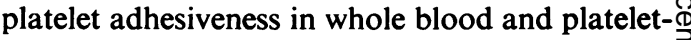
rich plasma.

Fractionation of the venom yielded six frac- $\stackrel{\mathbb{D}}{-}$ tions for further study. One fraction was shown to $\overrightarrow{0}$ possess marked anticoagulant activity; the other $\delta$ five fractions shortened the plasma recalcification time. The anticoagulant fraction was the only one to show antiplasmin action, the other five fractions $\frac{}{-}$ having no effect on plasmin activity. It must be assumed that crude venom possesses a labile?

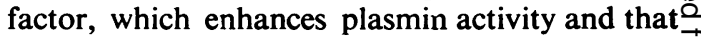
this activity has been lost in the process of $\overrightarrow{\overrightarrow{0}}$ fractionation. The fractions also had striking effects on platelets, and the variable effects of the crude venom can possibly be explained on the presence of fractions with opposing actions. Four fractions enhanced platelet ADP reactivity andoproduced platelet aggregation in the absence of 3 . ADP. One fraction had no action on plateletrich plasma in the absence of ADP but reduced platelet ADP reactivity. The sixth fraction, whicho was anticoagulant and inhibited plasmin, also inhibited the action of ADP. This fraction waso capable of increasing the optical density of platelet-rich plasma in the presence or absence of ADP. 0 Light microscopy failed to show any morpho- N logical change in the platelets. That this effect ${ }_{\mathbb{W}}$ was due to an action on the platelets was proveno by the failure of the fraction to alter the opticato density of platelet-poor plasma.

In view of the importance of platelets in thrombus formation and the current interest in 0 substances which modify platelet behaviour, it is ${ }_{0}^{\circ}$ considered that this fraction is worthy of further $\stackrel{\odot}{\circ}$ study.

We are grateful to Mr J. Leakey who supplied thes venom. We are also indebted to Professor S. $\frac{\bar{C}}{\bar{C}}$ 
Alstead and Professor A. S. Douglas for their continued interest.

Financial assistance was provided by the Kenya Ministry of Health, East African Medical Research Council, Ministry of Overseas Development, Hoechst (East Africa) Ltd, Pfizer Tropical Research Laboratory, Merck, Sharp and Dohme Research Laboratories, the Pfizer Corporation, and Imperial Chemical Industries, Pharmaceuticals Division.

\section{References}

Alkjaersig, N. (1960). Proceedings of the Conference on Thrombolytic Agents. Edited by H. R. Roberts and J. D. Geraty, University of N. Carolina, Chapel Hill.

Biggs, R., and Douglas, A. S. (1953). The thromboplastin generation test. J. clin. Path., 6, 23-29.

Biggs, R., and Macfarlane, R. G. (1962). Human Blood Coagulation and its Disorders. Blackwell, Oxford.

Born, G. V. R., and Cross, M. J. (1963). Effect of adenosine diphosphate on the concentration of platelets in circulating blood. Nature (Lond.), 197, 974-976.

Bücherl, W., Buckley, E. E., and Deulofeu, V. (1968). Venomous Animals and Their Venoms, Vol. 1. Academic Press, New York.
Chandler, A. B. (1958). In vitro thrombotic coagulation of the blood. Lab. Invest., 7, 110-114.

Cunningham, G. M., McNicol, G. P., and Douglas, A.S. (1965ఖ Effect of anticoagulant drugs on platelet aggregation in the Chandler's tube. Lancet, 1, 729-730.

Douglas, A. S. (1962). Anticoagulant Therapy. Blackwell, Oxford:

Forbes, C. D., Turpie, A. G. G., McNicol, G. P., and Douglas, S. (1966). Studies on East African snakes: mode of action of Echis carinatus venom. Scot. med. J., 11, 168-17श

Hellem, A. J. (1960). The adhesiveness of human blood platele in vitro. Scand. J. clin. Lab. Invest., 12, Suppl. 51

Kirk, R., and Corkill, N. L. (1946). Venom of the rhinoceros viper, Bitis nasicornis (Shaw). J. trop. Med. Hyg., 49, 9-1థ

MacKay, N., Ferguson, J. C., Ashe, J., Bagshawe, A., Forrester, A. T. T., and McNicol, G. P. (1969). The venom of the boomslang (Dispholidus typus): In vivo and in vitro studies. Thrombos. Diathes. haemorrh. (Stuttg.), 21, 234-244.

McNicol, G. P., and Douglas, A. S. (1964). The firbinolytici enzyme system. In Recent Advances in Clinical Patholog edited by S. C. Dyke, Series IV, p. 187. Churchill, Londo

Merskey, C. (1950). The consumption of prothrombin durind coagulation. The defect in haemophilia and thromb cytopenic purpura. J. clin. Path., 3, 130-141.

Nilsson, I. M., and Olow, B. (1962). Fibrinolysis induced boo streptokinase in man. Acta chir. scand., 123, 247-266.

Pitney, W. R., and Dacie, J. V. (1953). A simple method of studying the generation of thrombin in recalcifieg plasma. J. clin. Path., 6, 9-14.

Remmert, L. F., and Cohen, P. P. (1949). Partial purification an properties of a proteolytic enzyme of human serum. J. biol. Chem., 181, 431-448. 